\title{
Articular cartilage superficial zone collagen birefringence reduced and cartilage thickness increased before surface fibrillation in experimental osteoarthritis
}

Harri E Panula, Mika M Hyttinen, Jari P A Arokoski, Teemu K Långsjö, Alpo Pelttari, Ilkka Kiviranta, Heikki J Helminen

\begin{abstract}
Objectives-To investigate articular cartilage collagen network, thickness of birefringent cartilage zones, and glycosaminoglycan concentration in macroscopically normal looking knee joint cartilage of young beagles subjected to experimental slowly progressive osteoarthritis (OA).

Methods-OA was induced by a tibial $30^{\circ}$ valgus osteotomy in 15 female beagles at the age of 3 months. Fifteen sisters were controls. Cartilage specimens were collected seven (Group 1) and 18 months (Group 2) postoperatively. Collagen induced optical path difference and cartilage zone thickness measurements were determined from histological sections of articular cartilage with smooth and intact surface by computer assisted quantitative polarised light microscopy. Volume density of cartilage collagen fibrils was determined by image analysis from transmission electron micrographs and content of glycosaminoglycans by quantitative digital densitometry from histological sections.
\end{abstract}

Results-In the superficial zone of the lateral tibial and femoral cartilage, the collagen induced optical path difference (birefringence) decreased by 19 to $71 \%$ (p $<0.05$ ) seven months postoperatively. This suggests that severe superficial collagen fibril network deterioration took place, as 18 months postoperatively, macroscopic and microscopic OA was present in many cartilage areas. Thickness of the uncalcified cartilage increased while the superficial zone became thinner in the same sites. In operated dogs, glycosaminoglycan content first increased (Group 1) in the lateral tibial condyle and then decreased (Group 2) $(\mathrm{p}<0.05)$.

Conclusion-In this OA model, derangement of the superficial zone collagen network was the probable reason for birefringence reduction. This change occurred well before macroscopic $O A$. (Ann Rheum Dis 1998;57:237-245)

The normal biomechanical behaviour of a diarthrodial joint is dependent on the composition and ultrastructural organisation of the articular cartilage. ${ }^{1}$ The collagen network of articular cartilage protects the chondrocytes, resists tensile forces produced by compression as well as interstitial swelling, provides attachment for proteoglycans (PGs), and anchors the cartilage to the subchondral bone. Normally, articular cartilage that is regularly subjected to high levels of shear stress, like femur, shows a high degree of collagen orientation and a thick superficial zone. On the other hand, articular cartilage of tibia, covered partly by menisci and subjected more to weightbearing, is rich in PGs and has a thin superficial zone. ${ }^{2}{ }^{3}$ PGs are a major component of the extracellular matrix of articular cartilage, too, and they are vital in maintaining tissue function. ${ }^{45}$ Glycosaminoglycans of PGs bind large amounts of water causing a high swelling pressure in the cartilage and providing resiliency of the tissue. ${ }^{6}$ In osteoarthritis (OA) the properties of articular cartilage become inferior, but so far, there is little information about the exact site of initiation and progression of early OA. There is evidence that early OA changes can be observed as changes in biochemical composition (for example, decrease in PG content) of the superficial zone of articular cartilage. ${ }^{78}$ It has also been suggested that disruption or loosening of the collagen network in the superficial zone of articular cartilage is closely involved in the initiation of OA process. ${ }^{8-11}$ Decrease of superficial PG concentration and superficial collagen network disruption coincide with softening of the articular cartilage. ${ }^{12} 13$ Later focal disruptions of the cartilage surface appear with fissuring, resulting in fibrillation of the joint surface. Fissures penetrating more deeply into cartilage and eventually down to the subchondral bone lead to further roughening of the cartilage surface until complete abrasion of the joint surface develops. ${ }^{14} 15$

Animal models have been used to clarify the mechanisms that lead to OA. ${ }^{816-22}$ Sectioning of the canine anterior cruciate ligament cause joint instability and an initial disorganisation of articular cartilage collagen and a change in the orientation of collagen fibrils while at the same time the cartilage surface appears smooth and intact. ${ }^{10}$ Microscopically, loss of the specific stainability of PGs at the surface of cartilage is very typical of OA. Cell necrosis, degradation of intercellular matrix, and disorientation of the superficial collagen fibril network can be observed..$^{10112324}$ Later, focal disruption of the cartilage leads to fibrillation of the joint surface. 


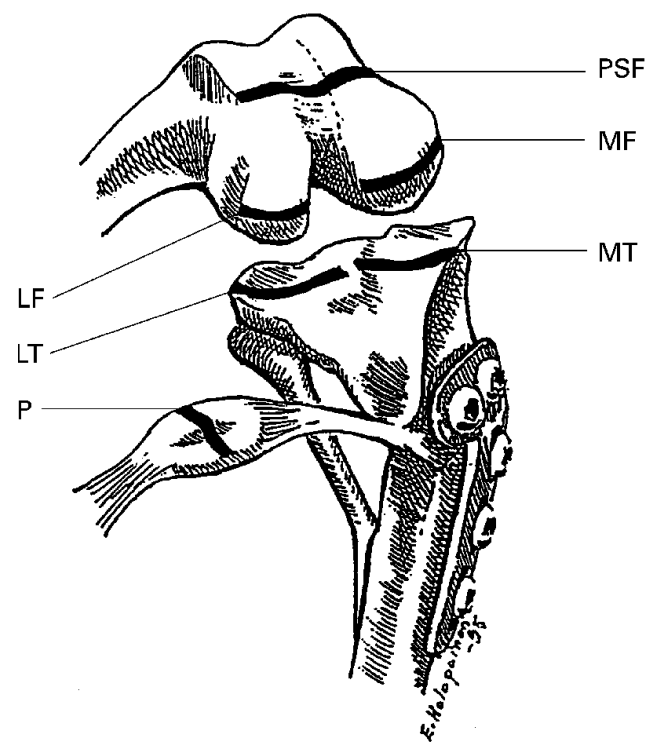

Figure 1 Sites of the polarised light microscopy analysis in the right knee (stifle) joint of valgus osteotomised dogs and controls. $P S F=$ patellar surface of femur, $P=$ patella, $L F=$ lateral condyle of femur, $M F=$ medial condyle of femur, $L T$ = lateral condyle of tibia and $M T=$ medial condyle of tibia. Samples from LF and LT were taken also for computer based digital densitometry and from LT for transmission electron microscopic analysis.

Despite wide knowledge of the general aetiopathology of OA, events in articular cartilage in the very beginning of the disease need further scrutiny. Recently, we have reported the effects of $30^{\circ}$ valgus angulation of tibia (valgus osteotomy) to induce slowly progressive OA cartilage lesions in stable knee (stifle) joints of young female beagle dogs. ${ }^{25}$ In this study we have used this model and quantitative polarised light microscopy to investigate the collagen network organisation, thickness of the birefringent zones, and PG concentration in the macroscopically intact articular cartilage. The study shows that beneath normal looking cartilage surface, an increase in uncalcified cartilage thickness with significant reduction of superficial zone collagen network and PG changes take place. We suggest that these changes precede the overt macroscopic OA changes present elsewhere in the cartilage surface.

\section{Methods}

ANIMALS, OPERATIVE PROCEDURES, AND

EUTHANASIA

Thirty female beagle dogs of pure breed were purchased from Marshall Farms (North Rose, NY, USA). The dogs were divided into two experimental groups, Group $1(\mathrm{n}=14)$ and
Group $2(\mathrm{n}=16)$. In each group the operated and a control dogs were littermates. A slowly progressive OA was induced in the right knee (stifle) joint of the dogs by a method described earlier. ${ }^{25}$ Briefly, a $30^{\circ}$ valgus angulation to the right tibia was created by operation in 15 dogs at the age of 3 months. The osteotomised tibia was internally fixed with a plate. Fifteen littermate animals served as controls, seven in Group 1 and eight in Group 2. The dogs were fed with commercial dog food (Vaasan Mylly Oy, Vaasa, Finland) 240 g per day. Water was given ad libitum. During the experiment the dogs were kept under kennel conditions in the National Laboratory Animal Centre (Karttula, Finland) where they lived in three dog fences. The design of the experiment was approved by the Animal Care and Use Committee of the University of Kuopio. The animals were killed by an overdose of anaesthetic seven (Group 1) and 18 months (Group 2) after operation. The hindlimbs were dissected free from the muscles and the knee (stifle) joints were opened. The macroscopic structure of the cartilage was examined and recorded.

\section{CARTILAGE SAMPLES}

Cartilage specimens were collected from the right knee (stifle) joint of the operated dogs and from controls. Samples for histological examination were harvested from the weightbearing condyles of femur and tibia, patella, and patellar surface of femur (fig 1). One mm thick cartilage slices were cut perpendicularly to the cartilage surface with underlying subchondral bone using a dentist's drill equipped with two cutting discs separated by a $1 \mathrm{~mm}$ spacer. As the sections cut parallel to the superficial split lines produce higher birefringence values than those cut perpendicularly, ${ }^{26}$ the cutting of the sections was done parallel to the superficial split lines. ${ }^{2}$ The split lines ran in the mediolateral direction on the weightbearing condyles of femur and tibia, whereas in the patellar surface of femur, and in the patella, no clear split line directions were observed. In the latter sites, sections were sawn in the mediolateral direction. During sawing, the specimens were fixed onto a ball joint specimen holder, which permitted perpendicular sawing of the cartilage sections. During preparation, the specimens were kept moist with ice cold $0.9 \%$ sodium chloride. After fixation for 48 hours in $4 \%$ (weight/volume, w/v) formaldehyde buffered to $\mathrm{pH} 7.0$, the samples were decalcified in $10 \%$ $(\mathrm{w} / \mathrm{v})$ EDTA in $4 \%(\mathrm{w} / \mathrm{v})$ formaldehyde, buffered to $\mathrm{pH} 7.4$, for 12 days at $4^{\circ} \mathrm{C}$. After

Table 1 Thickness of knee (stifle) joint articular cartilage (mean (SEM)) seven months (Group 1) after $30^{\circ}$ valgus osteotomy

\begin{tabular}{|c|c|c|c|c|c|c|c|c|c|}
\hline \multirow[b]{3}{*}{ Site of analysis } & \multicolumn{9}{|c|}{ Thickness of uncalcified cartilage $(\mu \mathrm{m})$} \\
\hline & \multicolumn{2}{|l|}{ Total } & \multirow{2}{*}{$\begin{array}{l}\text { Change } \\
(\%)\end{array}$} & \multicolumn{2}{|c|}{ Superficial zone } & \multirow{2}{*}{$\begin{array}{l}\text { Change } \\
(\%)\end{array}$} & \multicolumn{2}{|l|}{ Deep zone } & \multirow{2}{*}{$\begin{array}{l}\text { Change } \\
(\%)\end{array}$} \\
\hline & Control & Osteotomy & & Control & Osteotomy & & Control & Osteotomy & \\
\hline Lateral condyle of tibia & $557(46)$ & $1006(124)^{\star}$ & 81 & $39(6)$ & $19(3)^{\star}$ & -51 & $399(46)$ & $914(103)^{\star}$ & 129 \\
\hline Lateral condyle of femur & $584(89)$ & $659(76)^{\star}$ & 13 & $43(5)$ & $32(8)^{\star}$ & -26 & $422(84)$ & $508(50)^{\star}$ & 20 \\
\hline Patella & $486(35)$ & $542(50)^{\star}$ & 17 & $53(6)$ & $39(6)^{\star}$ & -67 & $371(36)$ & $427(47)^{\star}$ & 15 \\
\hline Patellar surface of femur & $456(41)$ & $532(90)$ & 17 & $46(15)$ & $37(16)$ & -20 & $333(41)$ & $412(80)$ & 24 \\
\hline Medial condyle of tibia & $720(89)$ & $780(83)$ & 8 & $29(6)$ & $34(11)$ & 17 & $586(192)$ & $684(102)$ & 17 \\
\hline Medial condyle of femur & $803(78)$ & $829(81)$ & 3 & $85(15)$ & $60(13)$ & -30 & $640(80)$ & $665(85)$ & 4 \\
\hline
\end{tabular}

$\mathrm{n}=7$ for operated and control dogs in Group 1. $\mathrm{n}=8$ for operated and control dogs in Group 2. ${ }^{\mathrm{p}}<0.05$ versus control. 
Table 2 Thickness of knee (stifle) joint articular cartilage (mean (SEM)) 18 months (Group 2) after $30^{\circ}$ valgus osteotomy

\begin{tabular}{|c|c|c|c|c|c|c|c|c|c|}
\hline \multirow[b]{3}{*}{ Site of analysis } & \multicolumn{9}{|c|}{ Thickness of uncalcified cartilage $(\mu m)$} \\
\hline & \multicolumn{2}{|l|}{ Total } & \multirow{2}{*}{$\begin{array}{l}\text { Change } \\
(\%)\end{array}$} & \multicolumn{2}{|c|}{ Superficial zone } & \multirow{2}{*}{$\begin{array}{l}\text { Change } \\
(\%)\end{array}$} & \multicolumn{2}{|l|}{ Deep zone } & \multirow[b]{2}{*}{ Change (\%) } \\
\hline & Control & Osteotomy & & Control & Osteotomy & & Control & Osteotomy & \\
\hline Lateral condyle of tibia & $706(119)$ & $764(135)$ & 8 & $35(6)$ & $25(7)$ & -29 & $535(128)$ & $612(158)$ & 14 \\
\hline Lateral condyle of femur & $664(32)$ & $784(88)^{\star}$ & 18 & $45(6)$ & $54(17)$ & 20 & $499(44)$ & $627(96)^{\star}$ & 26 \\
\hline Patella & $498(60)$ & $654(248)$ & 31 & $52(11)$ & $41(10)$ & -21 & $390(60)$ & $548(251)$ & 41 \\
\hline Patellar surface of femur & $466(46)$ & $613(138)^{\star}$ & 32 & $40(16)$ & $28(18)$ & -30 & $354(49)$ & $459(88)^{\star}$ & 30 \\
\hline Medial condyle of tibia & $770(199)$ & $716(143)$ & -7 & $33(7)$ & $31(9)$ & -6 & $630(206)$ & $555(186)$ & -12 \\
\hline Medial condyle of femur & $927(80)$ & $962(113)$ & 4 & $65(11)$ & $59(18)$ & -9 & $784(60)$ & $833(97)$ & 6 \\
\hline
\end{tabular}

$\mathrm{n}=7$ for operated and control dogs in Group 1. $\mathrm{n}=8$ for operated and control dogs in Group 2. ${ }^{\star} \mathrm{p}<0.05$ versus control.

alcohol dehydration, the specimens were infiltrated and embedded in Paraplast Plus wax (Lancer Division of Sherwood Medical, Kildare, Ireland). Histological sections, 5 or $3 \mu \mathrm{m}$ thick, were cut perpendicularly to the articular surface with an LKB 2218 HistoRange microtome (LKB-Produkter Ab, Bromma, Sweden), and dried overnight at $37^{\circ} \mathrm{C}$.

\section{CONVENTIONAL LIGHT MICROSCOPY OF}

CARTILAGE

The $5 \mu \mathrm{m}$ thick sections were stained after dewaxing and rehydration with Weigert's iron haematoxylin, safranin $\mathrm{O}$, and fast green. ${ }^{25}$ Mankin's scores were assessed from the histological sections as described earlier. ${ }^{25} 27$ The scores were given for the cartilage structure, cellularity, stainability of the cartilage with safranin $\mathrm{O}$, and the integrity of tidemark.

\section{SECTION TREATMENTS FOR COLLAGEN}

POLARISATION MICROSCOPY

From the $5 \mu \mathrm{m}$ thick sections Paraplast Plus wax was removed in xylene and the sections were taken into water through a descending series of ethanol. ${ }^{2}$ The sections were digested with bovine testicular hyaluronidase (Sigma
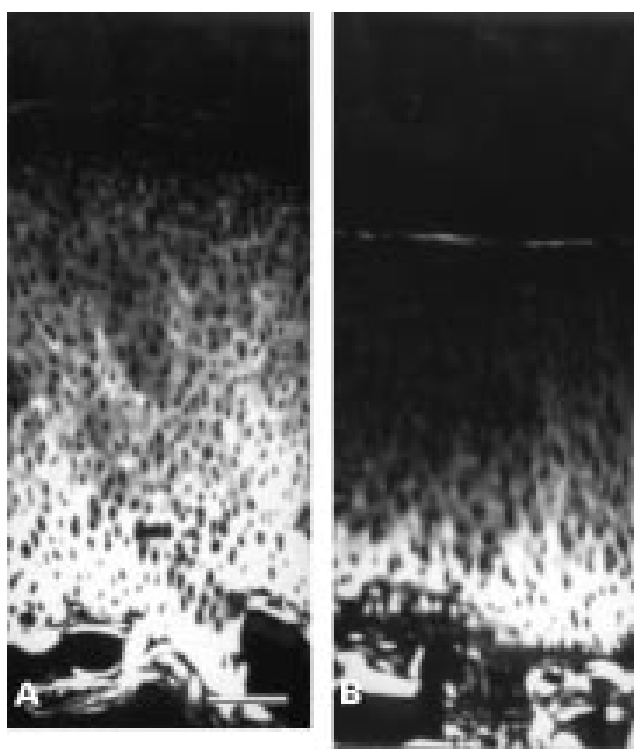

Figure 2 Polarised light micrographs taken from unstained sections of the articular cartilage from the lateral condyle of tibia (LT) from a valgus operated dog (seven months postoperatively) (A) and a littermate control $(B)$. Birefringence in the superficial zone of the operated dog is markedly decreased compared with control. On the other hand, in the deep zone birefringence is increased in the operated animal (scale $125 \mu \mathrm{m}$ ).
Chemical Co, St Louis, Mo, USA) to remove glycosaminoglycans. ${ }^{2}$ Finally, the sections were dehydrated in ethanol, cleared in xylene, and mounted with DPX (Gurr, BDH Laboratory Supplies, Poole, England).

POLARISED LIGHT MICROSCOPY OF CARTILAGE COLLAGEN FIBRILS

Birefringence of the sections were assessed from the superficial and deep zones of articular cartilage specimens by a method described recently by Arokoski et al. ${ }^{2}$ The computerised image analysis system for polarised light microscopy consisted of a Leitz Ortholux II POL polarised light microscope (Leitz Wetzlar, Wetzlar, Germany) connected to a thermoelectrically cooled camera Photometrics CH250/A (Photometrics Inc, Tucson, AZ, USA) including the Kodak KAF-1400 scientific grade charge coupled device (CCD) (Kodak, Rochester, NY, USA). Image capturing, processing, and analysis were carried out with IPLab Spectrum (Signal Analytics Corporation, Vienna, VA, USA) software. For polarised light microscopy, a strain free PL Fluotar $6.3 \times / 0.20$ NA objective was used. For transillumination of the specimens, monochromatic light (wavelength $=589 \mathrm{~nm}$ ) was used and it was adjusted with an interference filter (IL $589 \mathrm{~nm}$, (t $1 / 2$ width $10 \mathrm{~nm}$ ) Optometrics Inc, USA).

In polarised light microscopy, the anisotropic collagen fibril of articular cartilage causes an optical path difference (retardation, $\Gamma$ ) of the light. ${ }^{28}$ The birefringence of a collagen fibril in linearly polarised light is dependent on the angle between the axis of polarisation and the axis of the fibril and on the geometric thickness of the specimen or the structure. ${ }^{28}$ In cartilage section, $\Gamma$ depends also on the organisation (orientation) pattern of collagen fibrils or the density of collagen structures in the specimen, or both. ${ }^{29}$ In this study, the intensity of incident and emergent light as changed by the retardation of the object and polarisation system was measured. Light intensity data were converted to optical path difference according to Fresnel's general equation and Sènarmont method $^{230}$ as follows: $\Gamma=(\alpha \lambda) / 180^{\circ}$

where $\alpha=$ angle $\left({ }^{\circ}\right)$ value was derived from Fresnel's equation, $\lambda=$ the wavelength $(\mathrm{nm})$ of monochromatic light.

The anisotropic areas of superficial and deep zones of articular cartilage were analysed separately. The cartilage area chosen for analysis demonstrated a smooth and intact surface. Within the area of measurement the smallest area unit was a pixel, which was $3.6 \mu \mathrm{m} \times 3.6$ 

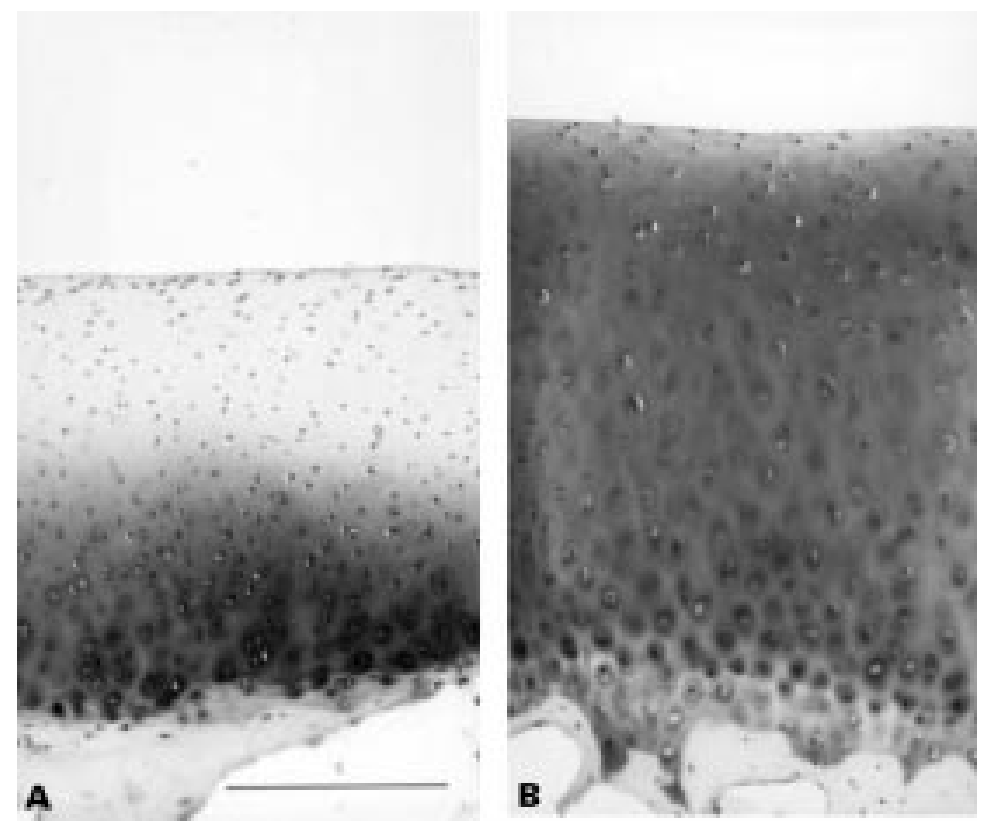

Figure 3 A photomicrograph taken from the lateral tibial (LT) condyle of the right knee joint 18 months after valgus osteotomy. In the superficial and intermediate zones of articular cartilage, severe reduction in safranin $O$ staining is evident. In this case, the thickness of uncalcified and calcified cartilage is reduced (A). A photomicrograph from the littermate control dog showing normal articular cartilage from the same area (B) (safranin $O$, fast green and iron haematoxylin, scale $250 \mu \mathrm{m}$ ).

$\mu \mathrm{m}$ at the specimen level. Measuring area width was set to $75 \times 3.6 \mu \mathrm{m}$ for the superficial, as well as for the deep zone. The beginning of the superficial zone and the tidemark were digitally marked. Based on these markings, the system generated the mean distribution of optical retardation and calculated cartilage thickness. The thickness of the superficial and deep zones of articular cartilage (mean (SEM)) were measured from the retardation distribution profile (tables 1 and 2).

The error between repeated measurements, the coefficient of variation (CV) (\%) of the AIR values between the measurements, the $\mathrm{CV}$ of the AIR values between sections of one tissue block, and the effect of orientation of the specimen on the values of AIR, was calculated as described earlier. ${ }^{2}$ The relative standard error of the mean $<10 \%$ was obtained when 1-3 sections were measured from more than four animals. ${ }^{2}$

Table 3 Mean area adjusted retardation value $\left(\Sigma \Gamma_{2}\right)$ (AIR) of the birefringent structure at different sites and zones of articular cartilage of the knee (stifle) joints after $30^{\circ}$ valgus osteotomy

\begin{tabular}{|c|c|c|c|c|c|}
\hline \multirow[b]{3}{*}{ Site of analysis } & \multirow[b]{3}{*}{ Ratiot } & \multicolumn{4}{|c|}{$A I R\left(n m / \mu m^{2}\right)$} \\
\hline & & \multicolumn{2}{|l|}{ Group 1} & \multicolumn{2}{|l|}{ Group 2} \\
\hline & & $\begin{array}{l}\text { Superficial } \\
\text { zone }\end{array}$ & $\begin{array}{l}\text { Deep } \\
\text { zone }\end{array}$ & $\begin{array}{l}\text { Superficial } \\
\text { zone }\end{array}$ & $\begin{array}{l}\text { Deep } \\
\text { zone }\end{array}$ \\
\hline Lateral condyle of tibia $\left(n_{I}=7\right),\left(n_{I I}=8\right)$ & $\mathrm{V} / \mathrm{C}$ & $0.29^{\star}$ & $1.43^{\star}$ & $0.56^{\star}$ & 1.07 \\
\hline Lateral condyle of femur $\left(n_{I}=7\right),\left(n_{I I}=8\right)$ & $\mathrm{V} / \mathrm{C}$ & $0.81^{\star}$ & 0.99 & 0.94 & 1.13 \\
\hline Patella $\left(n_{I}=7\right),\left(n_{I I}=8\right)$ & $\mathrm{V} / \mathrm{C}$ & $0.77^{\star}$ & 0.88 & 0.87 & 1.00 \\
\hline Patellar surface of femur $\left(n_{I}=7\right),\left(n_{I I}=8\right)$ & $\mathrm{V} / \mathrm{C}$ & 0.98 & 0.91 & 0.70 & 0.76 \\
\hline Medial condyle of tibia $\left(n_{I}=7\right),\left(n_{I I}=8\right)$ & $\mathrm{V} / \mathrm{C}$ & 1.27 & 1.10 & 0.86 & 0.88 \\
\hline Medial condyle of femur $\left(n_{I}=7\right),\left(n_{I I}=8\right)$ & $\mathrm{V} / \mathrm{C}$ & 0.94 & 0.96 & 0.75 & 1.05 \\
\hline
\end{tabular}

tRatio between the mean values of the right knee joint of valgus osteotomised and control dogs (V/C). $n_{\mathrm{I}}=$ Number of paired observations in Group 1. $\mathrm{n}_{\mathrm{II}}=$ Number of paired observations in Group $2 .{ }^{\star} \mathrm{p}<0.05$, by Wilcoxon matched pairs signed rank test.
TRANSMISSION ELECTRON MICROSCOPIC (TEM) ANALYSIS

Articular cartilage samples for TEM analysis were taken from the lateral tibial condyle. Cartilage sections, $0.5 \mathrm{~mm}$ thick, were sawn from the adjacent location and in the same direction as the specimens used in polarised light microscopy. Specimens were fixed for 24 hours in $2 \%$ $(\mathrm{w} / \mathrm{w})$ glutaraldehyde in $0.1 \mathrm{M}$ sodium cacodylate buffer, $\mathrm{pH} 7.2$, and decalcified in buffered $7.5 \%$ EDTA solution for 12 days. Samples were post-fixed in buffered $1 \%$ osmium tetroxide for two hours, dehydrated, and embedded in LX-112 epoxy resin. Ultrathin vertical sections with silver-gray interference colour were cut parallel to the main sawing direction using ultramicrotome, stained with $1 \%$ tannic acid, uranyl acetate, and lead citrate, ${ }^{31}$ and examined with a JEM-1200 EX transmission electron microscope (JEOL Ltd, Tokyo, Japan).

Five vertically successive TEM pictures from the superficial zone of the articular cartilage of the Group 2 animals, starting $3.7 \mu \mathrm{m}$ from the surface, were photographed with transmission electron microscope at $80 \mathrm{kV}$ acceleration voltage and with a magnification of $\times 15000$. TEM negatives were digitised on a light table with Photometrics 250 thermally stabilised, CCD camera, (resolution was $658 \times 517$ pixels) using IP-Lab Spectrum image analysis software. The final pixel area was $63 \mathrm{~nm}^{2}$.

Backround intensity of the image was corrected and the collagen fibrils were distinguished from the matrix with a flat fielding algorithm, in which the digitised image was at first duplicated. The duplicate was low pass filtered for 16 times. The filtered image was subtracted from the original one. This backround reduced image was binarised and the collagen volume fraction (\%) was measured by using NIH-Image image analysis program. The average collagen volume fraction for each animal was calculated.

SECTION TREATMENTS FOR PROTEOGLYCAN DENSITOMETRY

The $3 \mu \mathrm{m}$ thick sections were cut from specimens taken from the lateral condyles of femur and tibia. The specimen preparation protocol has been previously described by Király et al and Kiviranta et al. ${ }^{32}{ }^{33}$ All steps of tissue and section preparation were strictly standardised. Tissue sections were stained with safranin O (Fisher Scientific, Fair Lawn, NJ). To obtain matching staining of both control and experimental specimens, histological sections from each group of animals were stained in the same dye bath using a Varistan 24-2 staining device (Shandon Southern Products, Runcorn, UK).

DIGITAL DENSITOMETRY OF PROTEOGLYCANS The concentration of cationic safranin $\mathrm{O}$ stain that binds stoichiometrically to glycosaminoglycan polyanions in $\mathrm{PGs},{ }^{33}$ was determined with a computerised image analysis system. Light absorption of stain bound to tissue sections was quantified under monochromatic light with digital densitometry. The 


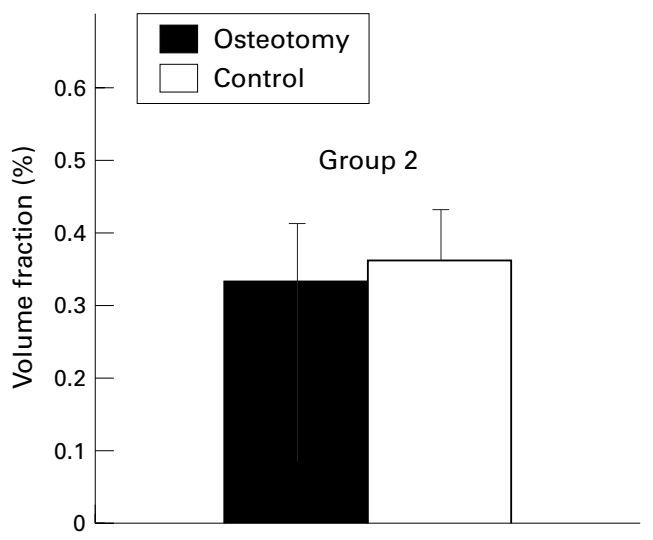

Figure 4 Volume fraction (\%) of collagen from the superficial zone of articular cartilage from the lateral condyle of tibia (LT) in operated and control dogs.

specimens were examined with the same analysing system (that is, microscope, camera, computer, and sofware) as the polarised light microscopy samples above. An interference filter (492 $\mathrm{nm} \pm 1 \%$, Spindler \& Hoyer, USA) was inserted into the light path to enhance light absorption caused by safranin $\mathrm{O} .^{34}$ The background image without a specimen containing possible optical defects and readout noise was registered. A neutral density filter set (Schott, Germany) ranging from 0 to 3.6 absorbance units was used for the ${ }^{10} \log$ based density calibration of the camera. The correlation coefficient $\left(r^{2}\right)$ was 0.996 for the camera gray response to the density change between 0 and 3.6 absorbance units, when the background image was subtracted from the image of interest. After calibration, gray values of the background subtracted real images were first converted to absorbance units according to the inverse absorbance-gray calibration function with IP-Lab software (Signal Analytics, VA, USA). The relation between the optical density of safranin $\mathrm{O}$ stained tissue sections and the fixed charge density of the same sections, derived mainly from the anionic GAGs, was linear (correlation coefficient $r^{2}=0.952$ ). Densitometry was performed starting from the superficial zone and ending down at the border between the calcified cartilage and subchondral bone. Two sections per tissue block were analysed. Measuring area was $75 \times 3.6 \mu \mathrm{m}$ wide. The measured region of interest, ranging from cartilage surface down to the border between the calcified cartilage and subchondral bone, was divided into 12 horizontal zones of equal thickness. The mode absorbance value was calculated along each pixel row within each of the 12 horizontal zones. The mode absorbance was adopted because it is insensitive to transmission of light through cell lacunae or other focal artefacts. Finally, four zones were made up for which the statistical analysis was carried out. The values from the first two horizontal zones (1/12 and 2/12, starting from cartilage surface) represented zones 1 and 2 (fig 5). Zone 3 represented values from horizontal zones $3 / 12$ to $7 / 12$, and zone 4 from horizontal zones $8 / 12$ to $12 / 12$. For these four zones the pixel integrated optical density was calculated. Pixel based optical density values were then converted to area integrated optical density (AIOD, $1 / \mathrm{nm}^{2}$ ).

STATISTICAL ANALYSIS

The Wilcoxon matched pairs signed ranks test and the Mann-Whitney U test were used to calculate statistical significance of differences between the operated and control dogs and between Group 1 and 2 dogs, respectively. A p value less than 0.05 was considered significant.

\section{Results}

MACROSCOPIC AND MICROSCOPIC FINDINGS

In the right knee joint of Group 1 animals two of the seven valgus operated dogs had subtle macroscopic and five of the seven dogs had initial microscopic changes in the cartilage as assessed by the scoring system of Mankin. ${ }^{25} 27$ In the right knee joint of Group 2 animals, five of the eight valgus osteotomised dogs had gross macroscopic cartilage lesions. ${ }^{25}$

In both valgus osteotomy groups, the histological changes exceeded the age matched control level $(\mathrm{p}<0.05)$ as assessed with the Mankin scoring system. The total scores summed up from all test points were 14 and 76 for Group 1 and Group 2, respectively. The histological changes were more severe in Group 2 than in Group 1 dogs ( $p<0.05)$. In both control groups the right knee joint cartilage showed no macroscopic or microscopic changes. Figures 2 and 3 show polarised and ordinary light microscopic changes, respectively, in the lateral condyle of tibia of Group 1 and Group 2 dogs.

THICKNESS OF UNCALCIFIED CARTILAGE AND DIFFERENT CARTILAGE ZONES

The thickness was determined from sections all showing smooth and intact cartilage surface. In Group 1 operated animals, the superficial zone of articular cartilage showed remarkable thinning in most sites examined (table 1). The reduction varied between $20 \%$ to $67 \%$ compared with controls. The reduction in thickness reached statistical significance in the lateral condyles of tibia and femur, and the patella ( $p$ $<0.05)$. In Group 2 operated animals the superficial zone reduced in thickness and the reduction varied between $6 \%$ and $30 \%$ depending on the site analysed (table 2 ).

In both groups, the deep zone and the total uncalcified cartilage increased in thickness in several test points (tables 1 and 2). The range of cartilage thickness increase was from 3\% to $81 \%$ and that of the deep zone from $4 \%$ to $129 \%$. The uncalcified cartilage of the lateral condyle of tibia was thicker in Group 1 than in Group 2 joints $(p<0.01)$.

Thus, in general, the thickness of the superficial zone decreased and that of the deep zone and of the total uncalcified articular cartilage increased. It is noteworthy that these results were from sites where cartilage surface was macroscopically intact. Changes in contrast with the general reaction pattern were observed in the medial condyle of tibia in Groups 1 and 2 (tables 1 and 2). 

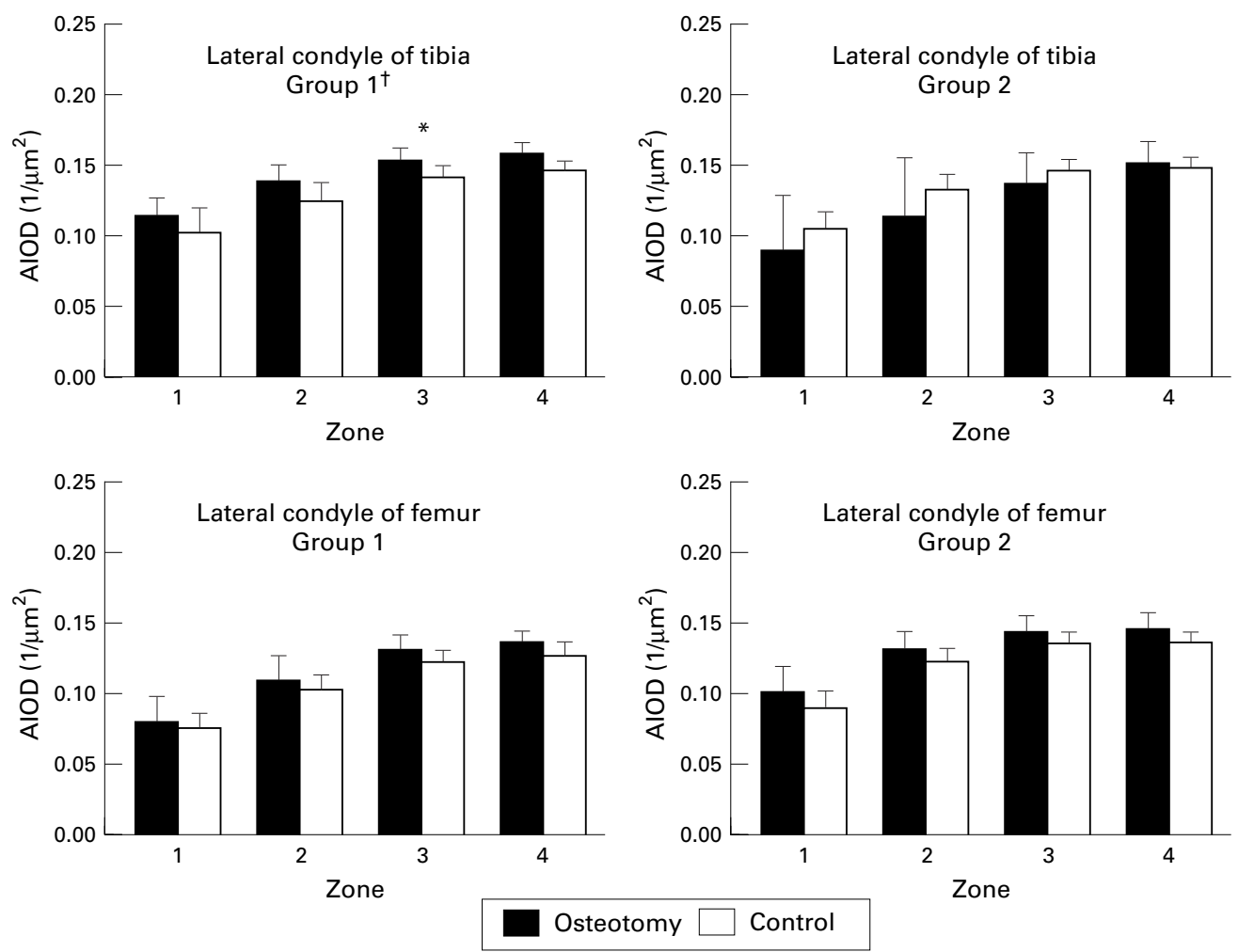

Figure 5 Histogram of the area integrated optical density (AIOD $\left.1 / \mu m^{2}\right)$ of safranin $O$ staining in articular cartilage from the lateral condyle of tibia (LT) and lateral condyle of femur (LF) divided to four zones 7 (Group 1) and 18 months (Group 2) postoperatively in valgus operated and control dogs. ${ }^{\star} p<0.05$ versus control, by Wilcoxon matched pairs signed ranks test. $\dagger p<0.05$ Group 1 versus Group 2, by Mann-Whitney $U$ test.

COLLAGEN FIBRIL ARRANGEMENT AND THE BIREFRINGENCE OF COLLAGEN

Collagen fibril arrangement was investigated from tissue sections showing smooth and intact cartilage surface. Areas with histological cartilage surface injury were excluded from these analyses. In this study, AIR is a measure of the amount, or degree of organisation, of the birefringent collagen/unit area. The mean values of AIR in the lateral condyles of tibia and femur, and patella, were smaller in Group 1 than in the controls $(\mathrm{p}<0.05)$ (table 3$)$. In these sites, AIR was reduced by $71 \%, 19 \%$ and $23 \%$, respectively.

In Group 2 operated animals, AIR of the superficial zone showed statistically significant $44 \%$ reduction in the lateral condyle of tibia. The medial condyle of tibia showed different response patterns in both groups (table 3 ). AIR of the deep zone was $43 \%$ higher in the operated dogs (Group 1) than in the controls (table 3).

VOLUME DENSITY OF COLLAGEN FIBRILS

Sections from the superficial zone of the lateral condyle of the tibia of Group 2 dogs, all showing smooth and intact cartilage surface, were chosen for the TEM analysis. The change of birefringence was marked in this location. Volume fraction (\%) of superficial collagen fibrils in the operated dogs did not differ from controls (fig 4).

DIGITAL DENSITOMETRY OF SAFRANIN O STAINED PROTEOGLYCANS

The digital densitometry analyses were performed exclusively from tissue sections having intact and smooth cartilage surface. Sections showing surface injuries were excluded. In the articular cartilage of operated dogs (Group 1), in the lateral condyle of tibia (zone 3), the proteoglycan content was higher than in controls $(\mathrm{p}<0.05)$ (fig 5). In the lateral tibial condyle, proteoglycan content was higher in Group 1 than in Group 2 operated animals $(p<0.05)$ (fig 5). In the lateral condyle of femur, proteoglycan content did not differ between the animals or groups.

\section{Discussion}

OA is a degenerative disorder of joints, characterised by deteorioration of the articulating joint surface. Eventually OA also leads to changes in the subchondral bone. In articular cartilage, collagen network is the key structure that supports the three dimensional architecture of the tissue. It is the collagen that provides articular cartilage with the tensile stiffness and strength and maintains its volume. ${ }^{35-37}$ In particular, the superficial zone of articular cartilage contains collagen fibrils that are orientated primarly parallel to the cartilage surface. ${ }^{30}$ These fibrils exert great influence on the biomechanical quality of cartilage. ${ }^{8}{ }^{38}$ Until now, assessment of the properties and integrity of the cartilage collagen network has been difficult. New techniques, however, have recently been adopted for this purpose, for example, image analysis of collagen fibrils from transmission electron micrographs, immunohistochemistry of collagen types and their breakdown products, and quantitative polarised light microscopy. The computer based quantitative 
polarised light microscopy method used in this study gives quantitative data on the organisation and properties of the collagen network of articular cartilage from unstained sections. ${ }^{2}$ The technique is suitable to detect even subtle changes of cartilage collagen network.

Recently, we have described a slowly progressive OA model in young female beagle dogs using high tibial $30^{\circ}$ valgus angulation..$^{25}$ In this model, seven months after surgery, initial microscopic articular cartilage changes were observed. These lesions progressed to OA during the following 11 months. Consequently, cartilage lesions, typical of $\mathrm{OA}$, were found on articular surfaces 18 months after the operation. It was concluded that the valgus osteotomy initiated OA changes on account of changed loading pattern of the knee joint. ${ }^{25}$ Apparently, the valgus osteotomy did not merely shift joint loading towards the lateral compartment of the knee joint but it also shifted patellar pull medially changing the patellofemoral articulation. At the same time, however, the knee remained stable. Interestingly, this study shows that the greatest cartilage thickness and collagen network changes occurred in the lateral compartment and the patellofemoral articulation of the knee joint.

The valgus osteotomy caused a striking decrease of birefringence in the superficial zone of macroscopically intact articular cartilage and an increase in total thickness of uncalcified articular cartilage seven months after osteotomy. These changes preceded the manifest OA observed in the joint surfaces 18 months after the surgery. At the same time as the superficial zone collagen birefringence was reduced a concomitant trend to birefringence increase in the deep zone of articular cartilage took place (table 3). This might have been a compensatory effort by the cartilage to withstand changed joint loading when the superficial zone collagen failed. In the light of earlier reports, the increase of cartilage thickness can be interpreted to represent a hypertrophic repair phase of canine OA. ${ }^{39-41}$ It can be hypothesised that thinning of the superficial zone of articular cartilage and reduction of its birefringence, which are indicative of collagen fibril breakdown or poor collagen organisation, made possible the thickening of the uncalcified cartilage by deficiently harnessed swelling pressure. It can be anticipated that the rarefied superficial collagen network was no longer able to resist the swelling pressure of PGs binding more water.

Although the sequence of events described above seems reasonable, even probable, there is room for other interpretations, too. Namely, another explanation for the decrease of superficial birefringence would be that the collagen fibrils change their global orientation through degradation and synthesis with reorientation of collagen fibrils. Increased collagen synthesis has been demonstrated in OA. ${ }^{82-44} \mathrm{We}$ assessed the volume fraction of collagen from the superficial zone of articular cartilage of the lateral condyle of tibia (Group 2). The volume fraction of collagen was not changed although the reduction of birefringence in this area was marked.

The changes were remarkable in the lateral compartment of the knee joint. Valgus osteotomy shifts weight to the lateral knee compartment, which consequently was exposed to heavier loads and changed shear stresses. Obviously, these changes were particularly detrimental to the superficial collagen network. Interestingly, we have observed that seven and 18 months after osteotomy, the concentrations of neutral metalloproteinase, stromelysin-1, and its tissue inhibitor, TIMP-1, were increased in the synovial fluid of the knee joint on the operated side. ${ }^{45}$ Stromelysin-1 has been suggested to be responsible for the degradation of cartilage matrix components (for example, aggrecan and link protein) and collagen (types II, IX, X, XI)..$^{46-48}$ Therefore we believe that, after the establishment of altered joint loading pattern by osteotomy, activation of the extracellular matrix degrading enzymes might have enhanced the breakdown of collagen fibrils and reduction of collagen induced birefringence.

Biomechanical factors play a critical part in the initiation and progression of OA. ${ }^{49-51}$ The sequence of events leading to the biochemical and biomechanical changes has remained unclear, however. In this study, changed joint loading caused a decrease of birefringence in the superficial zone of articular cartilage. Also increase of cartilage thickness was observed. The changes were of varying degree of severity in different joint regions. It seems reasonable to suggest that the cartilage changes were closely related to changed joint biomechanics and joint loading after the valgus osteotomy. In addition to extracellular proteinase action, a direct mechanical damage to the superficial collagen fibrils in the form of relative overloads, might have contributed to disorganisation of the superficial collagen network, on the lateral knee (stifle) joint compartment in particular. The different reaction pattern of the medial tibial cartilage from other test points can be explained by changed weightbearing (table 1 and 2). During the course of OA disease, the repair activity of articular cartilage was insufficient and macroscopic OA lesions became evident. ${ }^{25}$ These findings are consistent with the results from previous studies on joint loading and experimental OA. ${ }^{3} 1940415253$

It is noteworthy that the above changes took place before apparent cartilage surface damage. The findings are in accordance with those of Orford et $\mathrm{al}^{10}$ and Stockwell et al. ${ }^{11}$ These authors observed, in canine articular cartilage subjected to surgical division of the anterior cruciate ligament, deterioration of the collagen fibrils under an intact cartilage surface. Failure of the superficial collagen network causes a decrease in the the tensile stiffness of cartilage. ${ }^{855455}$ Thus, any degree of disorganisation of the collagen network, also evident in this study, weakens the cartilage matrix making it prone to damage and OA.

This study provides novel information about the structural changes of articular cartilage collagen fibrils during early OA. The superficial collagen network disorganisation seems to 
be one of the first structural changes before appearance of overt OA lesions. The concomitantly increased concentrations of matrix degrading metalloproteinases, for example, stromelysin-1, in synovial fluid may contribute to the derangement of the collagen network in cartilage.

This study was financially supported by the North-Savo Fund of the Finnish Cultural Foundation, the Orthopaedic and Traumatologic Research Foundation of Finland, the Paulo Foundation, and the Ministry of Education in Finland.

1 Mow VC, Ratcliffe A, Poole AR. Cartilage and diarthrodial joints as paradigms for hierarchial materials and structures. Biomaterials 1992;13:67-97.

2 Arokoski JPA, Hyttinen MM, Lapveteläinen T, Takács P, Kosztáczky B, Módis L, et al. Decreased birefringence of the superficial zone collagen network in the canine knee (stifle) articular cartilage after long distance running training, detected by quantitative polarised light microscopy. ing, detected by quantitative polaris
Ann Rheum Dis 1996;55:253-64.

3 Kiviranta I, Tammi M, Jurvelin J, Säämänen A-M, Helminen HJ. Moderate running exercise augments glycosaminoglycans and thickness of articular cartilage in
the knee joint of young beagle dogs. J Orthop Res 1988;6: the knee

4 Hardingham TE. Proteoglycans: Their structure, interactions and molecular organization in cartilage. Biochem Soc Trans 1981;9:489-97.

5 Muir H. Proteoglycans as organizers of the extracellular matrix. Biochem Soc Trans 1983;11:613-22.

6 Maroudas A. Balance between swelling pressure and collagen tension in normal and degenerate cartilage. Nature 1976;260:808-9.

7 Dunham J, Shackleton DR, Nahir AM, Billingham MEJ, Bitensky L, Chayen J, et al. Altered orientation of glycosaminoglycans and cellular changes in the tibial cartilage in the first two weeks of experimental osteoarthritis. J lage in the first two weeks of
Orthop Res 1985;3:258-68.

8 Guilak F, Ratcliffe A, Lane N, Rosenwasser MP, Mow VC. Mechanical and biochemical changes in the superficial zone of articular cartilage in canine experimental osteoarthritis. J Orthop Res 1994;12:474-84.

9 Adams ME. Cartilage hypertrophy following canine anterior cruciate ligament transection differs among differen areas of the joint. J Rheumatol 1989;16:818-24.

10 Orford CR, Gardner DL, O'Connor P. Ultrastructural changes in dog femoral condylar cartilage following
anterior cruciate ligament section. J Anat 1983;137:65363.

11 Stockwell RA, Billingham MEJ, Muir H. Ultrastructural changes in articular cartilage after experimental section of the anterior cruciate ligament of the dog knee. J Anat 1983; 136:425-39.

12 Bentley G, Dowd G, Orth MCh. Current concepts of etiology and treatment of chondromalacia patellae. Clin Orthop 1983;189:209-28.

13 Bentley G. Articular cartilage changes in chondromalacia patellae. J Bone Joint Surg 1985;67 B:769-74.

14 Byers PD, Maroudas A, Ozlop F, Stockwell R, Venn MF Histological and biochemical studies on cartilage from osteoarthrotic femoral heads with special reference to surface characteristics. Connect Tissue Res 1977;5:41-9.

15 Maroudas A, Venn M. Chemical composition and swelling of normal and osteoarthrotic femoral head cartilage. Ann Rheum Dis 1977;36:399-406.

16 Goodman SB, Lee J, Smith RL, Csongradi JC, Fornasier VL. Mechanical overload of a single compartment induces nary study. J Invest Surg 1991;4:161-70.

17 Johnson RG, Poole AR. Degenerative changes in dog articular cartilage induced by a unilateral tibial valgus osteotomy. Exp Pathol 1988;33:145-64.

18 Lovász G, Llinás A, Benya P, Bodey B, McKellop HA, Luck $\mathrm{JV} \mathrm{Jr}$, et al. Effects of valgus tibial angulation on cartilage degeneration in the rabbit knee. J Orthop Res 1995;13: 846-53.

19 McDevitt C, Gilbertson E, Muir H. An experimental model of osteoarthritis; early morphological and biochemical changes. J Bone Joint Surg 1977;59B:24-35.

20 Pond MJ, Nuki G. Experimentally induced osteoarthrosis in the dog. Ann Rheum Dis 1973;32:387-8.

21 Reimann I. Experimental osteoarthrosis of the knee in rabbits induced by alteration of the load-bearing. Acta Orthop Scand 1973;44:496-504.

22 Wu DD, Burr DB, Boyd RD, Radin EL. Bone and cartilage changes following experimental varus or valgus tibial angulation. J Orthop Res 1990;4:572-85.

23 Meachim G, Fergie IA. Morphological patterns of articular cartilage fibrillation. J Pathol 1975;102:1-8.

24 Muir H, Carney SL. Pathological and biochemical changes in cartilage and other tissues of the canine knee resulting from induced joint instability. In: Helminen HJ, Kiviranta I, Säämänen A-M, Tammi M, Paukkonen K, Jurvelin J, eds. foint loading. Biology and health of articular structures. Bristol: Woint loading. Biology and

25 Panula HE, Helminen HJ, Kiviranta I Slowly progressive osteoarthritis after tibial valgus osteotomy in young beagle dogs. Clin Orthop 1997;343:192-202.
26 Arokoski JPA, Hyttinen MM, Elo M, Helminen HJ. Collagen arrangement in the canine femoral and tibial cartilage. Transact Orthop Res Soc 1996;21:314

27 Mankin HJ, Dorfman H, Lippiello L, Zarins A. Biochemical and metabolic abnormalities in articular cartilage from osteo-arthritic human hips. J Bone Joint Surg 1971;53A: 523-37.

28 Bennett HS. Methods applicable to the study of both fresh and fixed materials. The microscopical investigation of biological materials with polarized light. In: McClung JR, ed. McClung's handbook of microscopical technique. New York:
Paul B Hoeber, 1950: 591-677.

29 Módis L. Extracellular matrix: a polarization microscopic approach. Boca Raton: CRC Press, 1991.

30 Benninghoff A. Form und Bau der Gelenkknorpel in ihren Beziehungen zur Funktion. Erste Mitteilung: Die modellierenden und formerhaltenden Faktoren des Knorpelreliefs. Z Gesamte Anatomie Abt1 1925;76:43-63.

31 Afzelius BA. Section staining for electron microscopy using tannic acid as a mordant: a simple method for visualization of glycogen and collagen. Microsc Res Tech 1992;21:6572 .

32 Király K, Lammi $M$, Arokoski J, Lapveteläinen T, Tammi $\mathrm{M}$, Helminen $\mathrm{HJ}$, et al. Safranin $\mathrm{O}$ reduces loss of glycosaminoglycans from bovine articular cartilage during histological specimen preparation. Histochem J 1996;28: 99-107.

33 Kiviranta I, Jurvelin J, Tammi M, Säämänen A-M, Helminen HJ. Microspectrophotometric quantitation of glycosaminoglycans in articular cartilage sections stained with safranin O. Histochemistry 1985;82:249-5

34 Király K, Lapveteläinen T, Arokoski J, Törrönen K, Modis L, Kiviranta I, et al. Application of selected cationic dyes for the semiquantitative estimation of glycosaminoglycans in histological sections of articular cartilage by microspectrophotometry. Histochem J 1996;28:577-90.

35 Kempson GE, Muir H, Pollard C, Tuke M. The tensile properties of the cartilage of human femoral condyles related to the content of collagen and glycosaminoglycans. Biochim Biophys Acta 1973;297:456-72.

36 Myers RR, Mow VC. Biomechanics of cartilage and and its response to biomechanical stimuli. In: Hall $\mathrm{BK}$, ed. Cartilage. Structure, function and biochemistry. New York: Academic Press, 1983: 313-41.

37 Schmidt MB, Mow VC, Chun LE, Eyre DR. Effects of proteoglycan extraction on the tensile behaviour of articular cartilage. J Orthop Res 1990;8:353-63.

38 Arokoski J, Jurvelin J, Kiviranta I, Tammi M, Helminen HJ. Softening of the lateral condyle articular cartilage in the canine knee joint after long distance (up to $40 \mathrm{~km} /$ day) running training lasting one year. Int $\mathrm{J}$ Sports Med 1994;15:254-60.

39 Adams ME, Brandt KD. Hypertrophic repair of canine articular cartilage in osteoarthritis after anterior cruciate articular cartilage in osteoarthritis after anterior cr
ligament transection. J Rheumatol 1991;18:428-35.

40 Brandt KD, Myers SL, Burr D, Albrecht M. Osteoarthritic changes in canine articular cartilage, subchondral bone, and synovium fifty-four months after transection of the anterior cruciate ligament. Arthritis Rheum 1991;34: 1560-70.

41 Vignon E, Arlot M, Hartman D, Moyer B, Ville G. Hypertrophic repair of articular cartilage in experimental osteoarthrosis. Ann Rheum Dis 1983;142:82-8.

42 Eyre DR, McDevitt CA, Billingham MEJ, Muir H. Biosynthesis of collagen and other matrix proteins by articular cartilage in experimental osteoarthrosis. Biochem J 1980; 188:823-37.

43 Lippiello L, Hall D, Mankin H. Collagen synthesis in normal and osteoarthritic human cartilage. J Clin Invest 1977;59:593

44 Sandy JD, Adams ME, Billingham MEJ, Plaas A, Muir H. In vivo and in vitro stimulation of chondrocyte biosynthetic activity in early experimental osteoarthritis. Arthritis Rheum 1984;27:388-97.

45 Panula HE, Lohmander LS, Rönkkö S, Ågren U, Helminen HJ, Kiviranta I. Elevated levels of synovial PLA $\mathrm{PL}_{2}$, stromelysin (MMP-3) and TIMP in early osteoarthrosis after tibial valgus osteotomy in young beagle dogs. Acta Orthop Scand (in press.)

46 Flannery CR, Lark MW, Sandy JD. Identification of a stromelysin cleavage site within interglobular domain of human aggrecan. J Biol Chem 1991;267:1008-14.

47 Nguyen Q, Murphy G, Roughley PJ, Mort JS. Proteoglycan aggregate degradation by a cartilage metalloproteinase. tion of link protein heterogeneity in situ. Biochem J 1989; tion of link

48 Wu JJ, Lark MW, Chun LE, Eyre Dr. Sites of stromelysin cleavage in collagen types II, IX, X and XI of cartilage. J Biol Chem 1991;266:5625-8.

49 Howell DS, Treadwell BV, Trippel SB: Etiopathogenesis of osteoarthritis. In: Moskowitz RW, Howell DS, Goldberg VM, Mankin HJ, eds. Osteoarthritis: diagnosis and medicall surgical management. 2nd ed. Philadelphia: WB Saunders, 1992: 233-52

50 Moskowitz RW. Experimental models of osteoarthritis. In: Moskowitz RW, Howell DS, Goldberg VM, Mankin HJ, eds. Osteoarthritis: diagnosis and medical/surgical manage-
ment. 2nd ed. Philadelphia: WB Saunders, 1992: 213-32.

51 Peyron JG, Altman RD. The epidemiology of osteoarthritis. In: Moskowitz RW, Howell DS, Goldberg VM, Mankin HJ, eds. Osteoarthritis: diagnosis and medical/surgical manage-
ment. 2nd ed. Philadelphia: WB Saunders, 1992: 15-37. 
52 Arokoski J, Kiviranta I, Jurvelin J, Tammi M, Helminen HJ. Long-distance running causes site-dependent decrease of cartilage glycosaminoglycan content in the knee joints of beagle dogs. Arthritis Rheum 1993;36:1451-9.

$53 \mathrm{McDevitt}$ CA, Muir H. Biochemical changes in the cartilage of the knee in experimental and natural osteoarthritis in the dog. J Bone Joint Surg 1976;58B:94-101.

54 Bader DL, Kempson GE, Egan J, Gilbey W, Barrett AJ.
The effects of selective matrix degradation on the short-term compressive properties of adult human articular cartilage. Biochim Biophys Acta 1992;1116:14754.

5 Mizrahi J, Maroudas A, Lanir Y, Ziv I, Webber TJ. The "instantaneous" deformation of cartilage: effects of collagen fiber orientation and osmotic stress. Biorheology 1986; 23:311-30. 